health. The splint was applied over the head, neck, and back and at the same time the patient was forbidden to speak. In three days the temperature was normal and the swollen glands disappeared. To-day sulphonamides or penicillin may be employed. At any rate fixation of the head and neck by means of a splint is an excellent treatment of inflammations in the neck region as well as injuries of the hypopharynx and upper parts of the oesophagus. - I am, etc.,

Wroclaw, Poland.

Stanisraw Tuszewski.

\section{Manifestations of Malnutrition}

SIR,-Reference Lieut.-Col. John Huston's letter (Sept. 20, p. 470), I feel he has not grasped the significance of the remarks of Dr. R. G. S. Whitfield and myself as regards epileptiform seizures. These epileptiform seizures were in relatively fit men, both in my case and in three-quarters of Dr. Whitfield's. The varying symptoms, signs, and seizures of the dying emaciated P.O.W. are tragically only too well remembered by most of us. I personally was not referring to these.-I am, etc., York.

LENOX MACFARLANE.

\section{Treatment of Varicose Veins}

SIR,-I was interested to read Prof. A. M. Boyd and Mr. D. J. Robertson's paper on varicose veins (Sept. 20, p. 452). Ligature of the great saphenous vein and all its tributaries is well recognized, but sometimes supplementary ligature of the small saphenous vein should be undertaken at the same time. I remember one case recently when varicosities had developed from both these veins, with apparently no pathological communication. Both showed impulses on coughing, and ligature of the great saphenous alone would not have sufficed to cure the condition. There is no doubt that multiple ligatures as suggested by Prof. Boyd should be more frequently performed than is at present the rule.

The danger of deep thrombosis following injection of sclerosing fluids at the time of operation has always struck me as being very real, and I abandoned this practice some years ago. The extensive thrombosis produced by this method I found truly terrifying, and I am grateful to Prof. Boyd for showing that my fear was more than theoretical. I find that, after satisfactory ligature or ligatures as the case may require, injections may be unnecessary altogether, or at the most one or two may be done when the patient is again ambulant; injection is then much safer. I often think that the minor complaints of humanity are overlooked by research workers, but I think their satisfactory treatment is as important as more spectacular diseases. -I am, etc.,

Newcastle-upon-Tyne.

F. Denis Hindmarsh.

\section{Causalgia of the Face}

Sir,-Mr. C. H. Cullen (Sept. 13, p. 433) draws attention to what he suggests may be a possible fallacy in the reasoning which led me to conclude that in at least some cases of causalgic pain there is a pain pathway by way of the sympathetic chain. He says the stimulus I applied (pressure on, and squeezing of, the superior cervical ganglion) may not have produced sufficient efferent sympathetic impulses to give rise to pain. Mr. Cullen must therefore consider that sympathetic impulses concerned in the maintenance of normal sympathetic tone are greater in number than those produced by such stimulation, as in his view causalgic pain is produced by these normal sympathetic impulses acting on afferent nerve fibres at the site of nerve injury. It seems to me, however, that stimulation such as I carried out would produce a much greater number of nerve impulses than those normally present. Certainly pinching motor fibres produced a greater flow of nerve impulses than are concerned in the maintenance of normal muscle tone. This is so whether the nerve trunk central to the point of stimulation has been blocked with procaine or not.

Mr. Cullen concludes his letter by describing two cases in which he stimulated with a faradic current the peripheral end of a sectioned sympathetic chain without reproducing the causalgic pain that had been present. This is valuable confirmation of my own finding, the only difference between $\mathrm{Mr}$. Cullen's experiment and my own being the nature of the stimulus employed. It is difficult to accept the view that stimu- lation with a faradic current was not sufficient to produce at least as great a discharge of nerve impulse as is required to maintain normal sympathetic tone. Surely a more reasonable conclusion from these observations is the one I drew-that sectioning the sympathetic chain had divided the pain pathway. If there should be any doubt whether such stimulation is adequate it should prove possible by means of electrical recording of action potentials to compare the number of nerve impulses maintaining normal tone with the number produced by such a stimulus. - I am, etc.,

Belfast.

J. A. W. Bingham.

\section{Spontaneous Haemopneumothorax}

SiR,-The two cases of spontaneous haemopneumothorax reported by Dr. J. K. McMyn (Sept. 13, p. 419) are good illustrations of the usual three phases (pain, improvement, signs of internal haemorrhage) in the sequence of events first described by Koral, E. (Amer. Rev. Tuberc., 1936, 33, 185), when intrapleural bleeding complicates spontaneous pneumothorax. I think, however, that it is not sufficiently sealized that the interval between the onset of pnetrmothorax and the occurrence of clear evidence of serious haemorrhage may be as short as a few hours.

The chief danger facing the patient who has sustained a spontaneous pneumothorax is generally stated to be a further escape of air and a valve-like action of a kinked bronchus causing a pneumothorax suffocant. Internal haemorrhage is a rare but equally dangerous and sometimes hardly less dramatic emergency which should be watched for in every patient who suffers a pleuro-pulmonary perforation.-I am, etc.,
Enfield, Middlesex.
C. Allan Birch.

\section{Hypoglycaemia following Partial Gastrectomy}

SIR,-Dr. R. D. Lawrence's letter (Sept. 20, p. 470) calls attention to the fact that in the paper by Prof. Dunlop and myself on hypoglycaemia following partial gastrectomy (Aug. 30, p. 330) no reference is made to his previous artic'e in the Journal $(1936,1,526)$. In it he describes several of the features of the post-operative blood sugar curves which we have since confirmed. His paper was entirly concerned with the hyperglycaemic phase in such curves, whereas we were particularly interested in the subsequent reactionary hypoglycaemia. Thus, in looking up the literature on hypoglycaemia we failed to note his paper on "Glycosuria of the "Lag Storage' Type-an Explanation" (oxyhyperglycaemia), which was actually, however, very germane to our subject. We therefore owe him an apology for our oversight.-I am, etc.,

Edinburgh.

\section{J. A. L. Gilbert.}

\section{The Lazy Eye}

SIR,-One sympathizes with Dr. William Moodie's concern (Aug. 23, p. 310) that the treatment of an amblyopic eye by occlusion of its fellow may result in educational backwardness and even initiate a neurosis. It is true that this treatment must inevitably subject the child to a certain amount of nerve strain and restrict its normal activities, but a grave disservice would be done to children with amblyopia if adverse criticisms of a valuable method of treatment were allowed to pass without further comment.

Dr. Moodie's suggestion that the rational treatment for amblyopia should be "optical" as it is an optical condition cannot be accepted. The essential lesion of true amblyopia lies in the psychological phase of the visual arc, a view that is confirmed by the mode of development by histological studies of amblyopic eyes, and by its response to treatment. There is ample clinical evidence that vision in these eyes will frequently improve, even late in life, under the psychological stimulus of the loss of the fellow functioning eye or following treatment by suggestion.

The statement that treatment by occlusion results in educational backwardness and may initiate neurosis requires qualification. As a group, children with squint show a high incidence of left-handedness and emotional instability, but occlusion cannot be blamed for a state of affairs which exists before the treatment is commenced. Children usually enjoy orthoptic training, and the exceptional case which does not tolerate the psychological strain of occlusion must have the treatment 